\title{
The impact of hydrological parameters on modelling slope safety factor towards shallow landslides: a case study from Oltrepò Pavese
}

\author{
M. Bordoni ${ }^{1 a}$, C. Meisina ${ }^{1}$, R. Valentino ${ }^{2}$, M.G. Persichillo ${ }^{1}$, M. Bittelli ${ }^{3}$ and S. Chersich ${ }^{1}$ \\ ${ }^{1}$ University of Pavia, Department of Earth and Environmental Sciences, 27100 Via Ferrata 1 Pavia, Italy \\ ${ }^{2}$ University of Parma, Department of Civil and Environmental Engineering and Architecture, 43100 Viale G.P. Usberti 181/A Parma, Italy \\ ${ }^{3}$ University of Bologna, Department of Agricultural Sciences, 40127 Viale Fanin 44 Bologna, Italy
}

\begin{abstract}
Hydrological monitoring of slope susceptible to shallow landslides allows for identifying the triggering conditions of shallow failures and implementing slope stability analysis at site-specific scale. In this work, a case study of a long-term hydrological monitoring in a slope susceptible to shallow landslides of Oltrepò Pavese (Northern Italy) is presented. The triggering mechanism develops in wet seasons (winter and spring) due to the uprise of a perched water table at about $1 \mathrm{~m}$ from ground surface, in consequence of the most intense rainfalls (about $>60 \mathrm{~mm}$ in $48 \mathrm{~h}$ ). Unstable conditions (safety factor $<1.0$ ) are correctly modeled on the basis of both water content and pore water pressure, with a better prediction considering hysteresis effects. Safety factor on the basis of water content can correctly assess the triggering conditions for unsaturated and completely saturated soils. It is possible estimating shallow landslides triggering caused by positive pore water pressures only considering this parameter.
\end{abstract}

\section{Introduction}

Rainfall-induced shallow landslides involve the slope materials till less than $2.0 \mathrm{~m}$ from ground. Due to their proximity to urbanized areas, they cause significant damages to structures and infrastructures and, sometimes, human losses [1].

In the last years, several authors identified different soil hydro-mechanical behaviors leading to shallow landslides triggering through the application of monitoring tools [2-4]. Moreover, monitoring data revealed very useful to be implemented in different kinds of physically-based methods for the assessment of slope stability at site-specific and local scales [5-6]. Monitoring devices improve the correct identification of shallow landslides triggering moments and of the areas which could be threatened by this kind of instability.

In this work, a case study of a long-term hydrological monitoring of a slope susceptible to shallow landslides is presented. The research aimed at investigating the triggering mechanism and implementing slope stability analyses. The study area is located in Oltrepò Pavese (Northern Italy). The monitoring period covers more than 3 years (42 months). The main objectives of the research are: 1) analyzing the main hydrological behaviors of the test-site slope soil based on field monitoring, in particular for identifying the soil hydrological conditions which can lead to shallow failures; 2) evaluating the effect of the soil hydrological parameters on modeling the safety factor at site-specific scale, using the data collected through the monitoring equipment.

\section{Material and methods}

\subsection{The study site}

The monitored slope is located in north-eastern Oltrepò Pavese, in correspondence of the northern termination of Pavese Apennines (Fig. 1). This slope is representative of other sites in this area prone to shallow landslides.

The topographic gradient is medium-high $\left(26-35^{\circ}\right)$. The slope is east-facing. Its elevation ranges from 210 to $170 \mathrm{~m}$ a.s.l., with the monitoring station located at $185 \mathrm{~m}$. a.s.l. The land use is mainly constituted by grass and shrubs. The climatic regime is temperate/mesothermal with a mean yearly air temperature of $12{ }^{\circ} \mathrm{C}$ and a mean yearly rainfall amount of $684.4 \mathrm{~mm}$. The bedrock is made of gravel, sand and poorly cemented conglomerates. Superficial soils, derived by bedrock weathering, are prevalently clayey-sandy silts and clayey-silty sands with different amount of pebbles and carbonate soft nodules. Soil thickness ranges between 0.5 to $1.85 \mathrm{~m}$, increasing from the top to the bottom of the slopes.

The area where the study slope is located is characterized by a high density of past rainfall-induced shallow landslides (Fig. 1). The first and most significant event occurred on 27-28 April 2009, due to an extreme rainfall of $160 \mathrm{~mm}$ of cumulated rain in $62 \mathrm{~h} \mathrm{[1]}$. Further shallow landslides occurred in the period between March and April 2013, and between 28 February and 2 March 2014 [7]. In particular, the study slope was affected by shallow failure on 27-28 April 2009 and 28 February-2

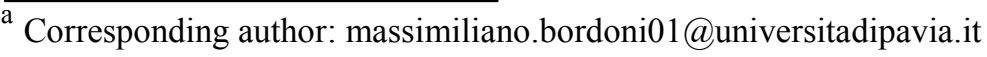




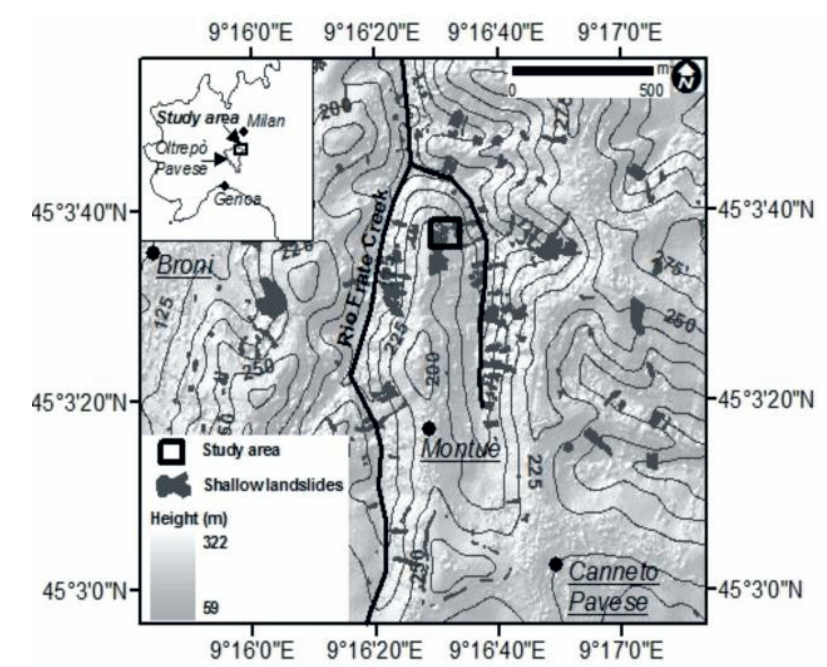

Figure 1. Location of the study area.

March 2014 events. The last event occurred $15 \mathrm{~m}$ far from the monitoring station (Fig. 1) during the monitoring activities. The source area had the same slope angle of the zone where the monitoring station is located $\left(30^{\circ}\right)$, and the failure surface developed at $1.0 \mathrm{~m}$ from the ground.

\subsection{Soil properties of the test-site slope}

A multidisciplinary study was carried out to characterize the superficial soils and the weathered bedrock of the study slope. A pedological description of the representative soil was performed in correspondence of the monitoring station. The soil is classified as Calcic Gleysol (Abruptic, Siltic) [8], with five main soil horizons (Tabs. 1, 2). The weathered bedrock (R) was identified at $1.3 \mathrm{~m}$ from the ground level.

Table 1. Grain size distribution of test-site slope soils and weathered bedrock.

\begin{tabular}{|c|c|c|c|c|c|}
\hline & $\begin{array}{c}\text { Representative } \\
\text { depth }\end{array}$ & $\begin{array}{c}\text { Gravel } \\
(>\mathbf{2} \mathbf{~ m m})\end{array}$ & $\begin{array}{c}\text { Sand } \\
\mathbf{( 2} \mathbf{~ m m}- \\
\mathbf{0 . 7 5} \mathbf{~ m m})\end{array}$ & $\begin{array}{c}\text { Silt } \\
\mathbf{( 0 . 7 5} \\
\mathbf{m m - 2} \\
\boldsymbol{\mu m})\end{array}$ & $\begin{array}{c}\text { Clay } \\
(<\mathbf{2} \boldsymbol{\mu m})\end{array}$ \\
\cline { 2 - 6 } & $\mathrm{m}$ & $\%$ & $\%$ & $\%$ & $\%$ \\
\hline $\mathrm{C}$ & 0.2 & 12.33 & 12.50 & 53.92 & 21.25 \\
\hline $\mathrm{D}$ & 0.4 & 1.50 & 11.40 & 59.42 & 27.68 \\
\hline $\mathrm{E}$ & 0.6 & 8.47 & 13.23 & 51.10 & 27.20 \\
\hline $\mathrm{F}$ & 1.0 & 2.40 & 12.20 & 56.40 & 29.00 \\
\hline $\mathrm{G}$ & 1.2 & 0.50 & 7.50 & 65.63 & 26.37 \\
\hline $\mathrm{R}$ & 1.4 & 0.20 & 75.00 & 24.80 & 0.00 \\
\hline
\end{tabular}

Soil horizons are calcareous (13.7-16.1\%). A calcic horizon was detected at $1.2 \mathrm{~m}$ from the ground (G level). In correspondence of this depth, the carbonate content is of $35.3 \%$. Soil horizons have a high silty content (51.1$65.6 \%$ ), that grows slightly with depth, and a clay content higher than $21.3 \%$ (Tab. 1). Sand and gravel contents are always low in the soil levels. They have lowest values in the $\mathrm{G}$ horizon (0.5 and 7.5\%, respectively). At $1.4 \mathrm{~m}$ from ground, the weathered bedrock (R) has a sandy texture, with a sand content of $75.0 \%$ (Tab. 1). According to USCS classification, soil horizons are prevalently non- plastic or slightly plastic soils (CL). Liquid limit $\left(\mathrm{w}_{\mathrm{L}}\right)$ ranges from 38.5 to $41.9 \%$, while plasticity index $\left(\mathrm{P}_{\mathrm{I}}\right)$ ranges between 14.3 and $17.2 \%$ (Tab. 2).

Table 2. Main geotechnical features of test-site slope soils and weathered bedrock.

\begin{tabular}{|c|c|c|c|c|c|c|}
\hline & $\begin{array}{c}\text { Representative } \\
\text { depth }\end{array}$ & $\mathbf{w}_{\mathbf{L}}$ & $\mathbf{P}_{\mathbf{I}}$ & $\boldsymbol{\gamma}$ & $\boldsymbol{\varphi}^{\prime}$ & $\mathbf{c}^{\prime}$ \\
\cline { 2 - 7 } & $\mathrm{m}$ & $\%$ & $\%$ & $\mathrm{kN} / \mathrm{m}^{3}$ & $\circ$ & $\mathrm{kPa}$ \\
\hline $\mathrm{C}$ & 0.2 & 39.79 & 17.18 & 17.00 & & \\
\hline $\mathrm{D}$ & 0.4 & 38.46 & 14.25 & 16.70 & & \\
\hline $\mathrm{E}$ & 0.6 & 40.32 & 15.65 & 16.70 & 31 & 0 \\
\hline $\mathrm{F}$ & 1.0 & 39.15 & 15.94 & 18.60 & 33 & 0 \\
\hline $\mathrm{G}$ & 1.2 & 41.85 & 16.54 & 18.25 & 26 & 29 \\
\hline $\mathrm{R}$ & 1.4 & - & - & 18.06 & & \\
\hline
\end{tabular}

Unit weight $(\gamma)$ trend is characterized by a significant increase in correspondence of the $\mathrm{F}$ horizon. This parameter passes from 16.7 to $18.6 \mathrm{kN} / \mathrm{m}^{3}$ at $1.0 \mathrm{~m}$ from ground and, then, keeps rather steady with depth (Tab. 2). Peak shear strength parameters were reconstructed for the E, F and $\mathrm{G}$ horizons through triaxial tests (Tab. 2). E and $\mathrm{F}$ horizons have friction angle $\left(\varphi^{\prime}\right)$ between $31^{\circ}$ and $33^{\circ}$ and nil effective cohesion ( $\left.c^{\prime}\right)$ (Tab. 2) The $G$ horizon is characterized by a friction angle of $26^{\circ}$ and an effective cohesion of $29 \mathrm{kPa}$ (Tab. 2).

\subsection{The monitoring equipment}

A more detailed description of the monitoring station is reported elsewhere [7]. In this paper, the necessary information required for completeness is provided. The station collects data with a time resolution of $10 \mathrm{~min}$. It measures: rainfall amount, air temperature, air humidity, atmospheric pressure, net solar radiation, wind speed and direction. Six Time Domain Reflectometer (TDR) probes measure the soil water content at $0.2,0.4,0.6,1.0,1.2$ and $1.4 \mathrm{~m}$ from the ground level. A combination of three tensiometers and three Heat Dissipation (HD) sensors measure the soil pore water pressure at $0.2,0.6$ and 1.2 $\mathrm{m}$. The HD sensors only allow for acquiring pore water pressures lower than $-10^{1} \mathrm{kPa}$ [3]; thus, tensiometers are installed to measure pore water pressures above $-10^{1} \mathrm{kPa}$. The field data are collected by a datalogger powered by a photovoltaic panel. In this work, field data acquired between 27 March 2012 and 27 October 2015 are analyzed.

\subsection{Model for slope stability analysis}

Lu and Godt's model (Eq. 1; [5]) was selected for slope stability analysis at site-specific scale.

$$
F_{S}=\frac{\tan \phi^{\prime}}{\tan \beta}+\frac{2 c^{\prime}}{\gamma z \sin 2 \beta}-\frac{\sigma^{s}}{\gamma z}\left[(\tan \beta+\cot \beta) \tan \phi^{\prime}\right]
$$

, where $\mathrm{F}_{\mathrm{s}}=$ slope safety factor; $\mathrm{c}^{\prime}=$ effective cohesion; $\gamma$ $=$ unit weight; $\mathrm{z}=$ depth below ground level in which $\mathrm{a}$ 

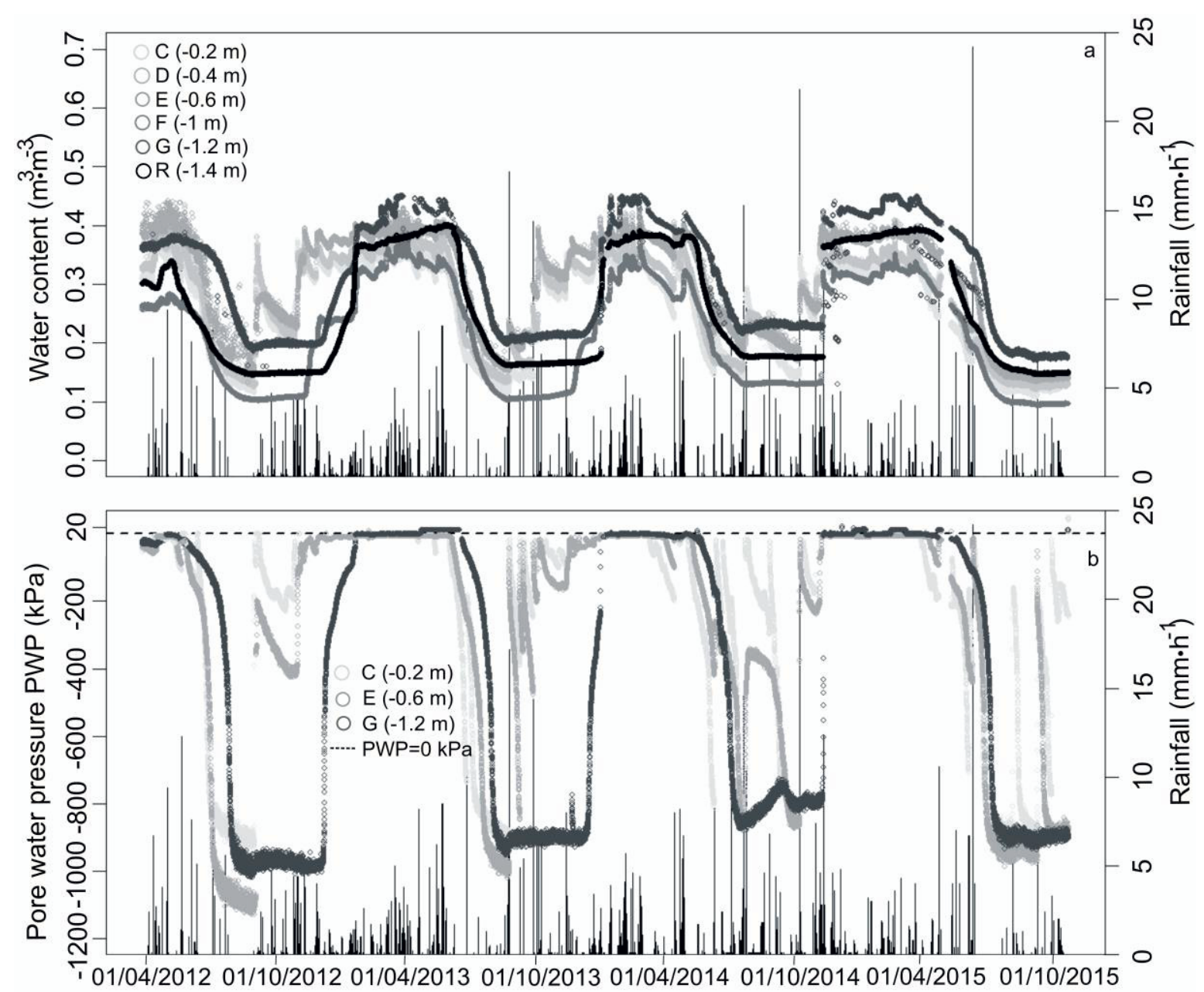

Figure 2. Water content (a) and pore water pressure (b) dynamics in relation with rainfalls for the analyzed time span.

potential sliding surface could develop; $\beta=$ slope angle; $\varphi^{\prime}=$ the friction angle; $\sigma^{\mathrm{s}}=$ suction stress.

The safety factor can be calculated alternatively by considering water content or pore water pressure and hydrological hysteresis, thanks to the term of suction stress (Eqs. 2-3). Thus the effects of these parameters on safety factor calculation can be highlighted

For modelling $\mathrm{F}_{\mathrm{s}}$ alternatively using water content or pore water pressure, suction stress was inserted in Eq. 1 through the following equation (Eqs. 2-3; [9]):

$$
\begin{aligned}
\sigma^{s} & =-\frac{S_{e}}{\alpha}\left(S_{e}^{\frac{n}{1-n}}-1\right)^{\frac{1}{n}} \\
\sigma^{s} & = \begin{cases}-\frac{\left(u_{a}-u_{w}\right)}{\left(1+\left(\alpha\left(u_{a}-u_{w}\right)\right)^{n}\right)^{\frac{n-1}{n}}} & \left(u_{a}-u_{w}\right)>0 \\
\left(u_{a}-u_{w}\right) & \left(u_{a}-u_{w}\right) \leq 0\end{cases}
\end{aligned}
$$

, where $\alpha$ and $\mathrm{n}=$ fitting parameters of the Soil Water Characteristic Curve (SWCC) [10]; $\theta_{\mathrm{s}}=$ saturated water content (measured through SWCC fitting); $\theta_{\mathrm{r}}=$ residual water content (measured through SWCC fitting).

\section{Results and discussions}

\subsection{Soil hydrological behaviors}

Average hourly values of collected data were analyzed to reproduce water content and pore water pressure dynamics both in the soil profile and in the weathered bedrock (Fig. 2). Due to breakage of the tensiometer, pore water pressure in the range higher than $-10^{1} \mathrm{kPa}$ was not measured at depth of $0.2 \mathrm{~m}$ since November 2012 .

In the analyzed period, water content ranged between 0.10 and $0.45 \mathrm{~m}^{3} \cdot \mathrm{m}^{-3}$ in the topsoil, and between 0.15 and $0.38 \mathrm{~m}^{3} \cdot \mathrm{m}^{-3}$ in the weathered bedrock. Instead, pore water pressure ranged from positive values, till $12.7 \mathrm{kPa}$ in the $\mathrm{G}$ horizon, to values in the order of $-10^{3} \mathrm{kPa}$.

Soil horizons till $0.6-0.7 \mathrm{~m}$ from the ground level had quick response than the deepest ones to long dry (summer months) or long wet (winter-spring months) periods (Fig. 2 ). On the other hand, only prolonged rainy periods, especially during winter months, can provoke an increase of the pore water pressure and of the water content in correspondence of soil horizons deeper than $0.6-0.7 \mathrm{~m}$ and of the weathered bedrock (Fig. 2).

During summer and early autumn rainfalls, the rewetting of the soil horizons till $0.6-0.7 \mathrm{~m}$ is very rapid (Fig. 2). Moreover, in correspondence of concentrated and moderately intense summer rainstorms, as on 27 June 2013 (13.3 $\mathrm{mm}$ in $2 \mathrm{~h}$ ), on 26 August 2013 (16.5 $\mathrm{mm}$ in 3 h), and on 14 June 2015 (39.7 $\mathrm{mm}$ in $6 \mathrm{~h}$ ), pore water pressure increase due to re-wetting is not coupled with a 


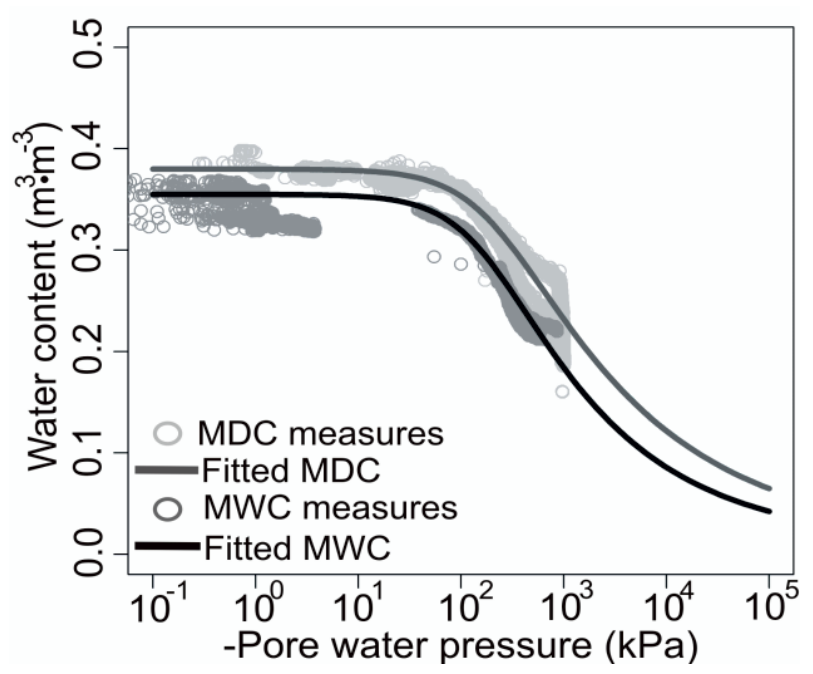

Figure 3. Example of field SWCC (G horizon).

Table 3. Van Genuchten equation fitting parameters of field fitted MDCs for the studied soil horizons.

\begin{tabular}{|c|c|c|c|c|c|}
\hline \multirow{2}{*}{} & \multicolumn{5}{|c|}{ MDC } \\
\cline { 2 - 6 } & $\boldsymbol{\alpha}_{\mathbf{d}}$ & $\mathbf{n}_{\mathbf{d}}$ & $\boldsymbol{\theta}_{\text {sd }}$ & $\boldsymbol{\theta}_{\text {rd }}$ & RMSE \\
\cline { 2 - 6 } & $\mathrm{kPa}^{-1}$ & - & $\mathrm{m}^{3} \cdot \mathrm{m}^{-3}$ & $\mathrm{~m}^{3} \cdot \mathrm{m}^{-3}$ & $\mathrm{~m}^{3} \cdot \mathrm{m}^{-3}$ \\
\hline $\mathrm{C}$ & 0.016 & 1.30 & 0.370 & 0.01 & 0.0159 \\
\hline $\mathrm{E}$ & 0.007 & 1.35 & 0.425 & 0.01 & 0.0165 \\
\hline $\mathrm{G}$ & 0.004 & 1.20 & 0.390 & 0.01 & 0.0092 \\
\hline
\end{tabular}

Table 4. Van Genuchten equation fitting parameters of field fitted MWCs for the studied soil horizons.

\begin{tabular}{|c|c|c|c|c|c|}
\hline \multirow{2}{*}{} & \multicolumn{5}{|c|}{ MWC } \\
\cline { 2 - 6 } & $\boldsymbol{\alpha}_{\mathbf{w}}$ & $\mathbf{n}_{\mathbf{w}}$ & $\boldsymbol{\theta}_{\text {sw }}$ & $\boldsymbol{\theta}_{\mathbf{r w}}$ & RMSE \\
\cline { 2 - 6 } & $\mathrm{kPa}^{-1}$ & - & $\mathrm{m}^{3} \cdot \mathrm{m}^{-3}$ & $\mathrm{~m}^{3} \cdot \mathrm{m}^{-3}$ & $\mathrm{~m}^{3} \cdot \mathrm{m}^{-3}$ \\
\hline $\mathrm{C}$ & - & - & - & - & - \\
\hline E & 0.010 & 1.43 & 0.395 & 0.01 & 0.0104 \\
\hline G & 0.006 & 1.26 & 0.370 & 0.01 & 0.0103 \\
\hline
\end{tabular}

correspondent increase in water content (Fig. 2). This behavior could be linked to non-equilibrium processes due to the fast infiltration phase [11] in which pore water pressure or water content trend lags behind each other by the SWCC equilibrium.

The months between December and May are the most wet periods. Frequent precipitations increase the soil wetness till it approaches or reaches saturated conditions. Completely saturated conditions were reached in the $G$ horizon in winters and springs, as testified by the values of pore water pressure around $0 \mathrm{kPa}$ (Fig. 2b). Rather prolonged rainy periods with many rainfall events could cause a further increase in pore water pressure, as occurred at the end of April-first day of May 2013, when pore water pressure reached $12.7 \mathrm{kPa}$ in the $\mathrm{G}$ horizon (Fig. 2b).

In wet periods, only the E horizon approaches saturated conditions, with pore water pressure increase till values of $-3 \mathrm{kPa}$, also in agreement with the highest values of measured soil water content at the same depth (around $0.40 \mathrm{~m}^{3} \cdot \mathrm{m}^{-3}$ ). During wetting periods, water content in the weathered bedrock was lower than in the overlying $G$ horizon (Fig. 2a). According to the monitored data, it could be supposed that during wet periods (winter and springs) a perched water table forms in the $G$ horizon. The upper soil levels could be saturated later, in correspondence of intense rainfalls ( $>60 \mathrm{~mm}$ in $48 \mathrm{~h}$ ), as observed in correspondence of 28 February-2 March 2014. In correspondence of this event, the $F$ horizon, which is positioned immediately above the G level, was affected by a significant increase of water content, passing from $0.32 \mathrm{~m}^{3} \mathrm{~m}^{-3}$ to values similar of those measured in the G horizon (Fig. 2). This increase leaded to the complete saturation of the F horizon as well, till 1.0 $\mathrm{m}$ from ground. This condition can be considered the triggering mechanism of rainfall-induced shallow landslides in the test-site slope.

Coupling contemporaneous field measurements of pore water pressure and water content allowed for reconstructing SWCCs for C, E and G layers. A Main Drying Curve (MDC) and a Main Wetting Curve can be identified (MWC) for both the E and the G layers, with a not-closed hysteretic behavior (Fig. 3). The drying path corresponded to the data measured in summer and autumn before the soil re-wetting, while the wetting path includes the values measured during the wet months (winter and spring).

Field measured data were interpolated by using Van Genuchten equation [13] through Marquardt algorithm [13] for evaluating the fitting parameters of the curves. Curve parameters $\left(\alpha, \mathrm{n}, \theta_{\mathrm{s}}, \theta_{\mathrm{r}}\right)$ changed passing from MDC to MWC, with a general increase in $\mathrm{n}$ and a decrease of $\alpha$ and $\theta_{\mathrm{s}}$ for the not-closed hysteresis (Tabs. $3,4)$. The reliability of the fitting procedure was good, as testified by the low values of Root Mean Square Error (RMSE) statistical index $\left(0.01-0.02 \mathrm{~m}^{3} \cdot \mathrm{m}^{-3}\right)($ Tab. 3, 4).

\subsection{Slope stability analysis}

Slope stability analysis was performed for the period between 28 February and 2 March 2014. Safety factor $\left(\mathrm{F}_{\mathrm{s}}\right)$ trends were reconstructed either from water content (Eq. 2) or pore water pressure (Eq. 3), considering, in both cases, the fitting parameters of drying or wetting curves (Fig. 4). These analyses were performed at 0.6 (E horizon), 1.0 (F horizon) and $1.2 \mathrm{~m}$ (G horizon) from ground level. For the $\mathrm{F}$ horizon, only the $\mathrm{F}_{\mathrm{s}}$ through water content could be reconstructed, for the loss of pore water pressure measurements at that depth.

The input soil geotechnical properties $\left(\gamma, \varphi^{\prime}, c^{\prime}\right)$ were provided in Tab. 2, while, the input hydrological properties were provided in Tabs. 3 and 4, by assigning to the $\mathrm{F}$ horizon the same values of the $\mathrm{E}$ level due to the similar grain size distribution and physical properties (Tabs. 1,2). The safety factor at a depth of $1 \mathrm{~m}$ decreases till unstable conditions on 1 March 2014 when calculated on the basis of the field measured water content only by using MWC parameters (Fig. 4a, b). This is consistent with the fact that shallow landslide occurred in wetting conditions of rainwater infiltration, thus the wetting parameters are more suitable than the drying ones.

At $1.2 \mathrm{~m}$ from the ground level, safety factor calculated from water content keeps constant for both MDC and MWC parameters due to the completely 

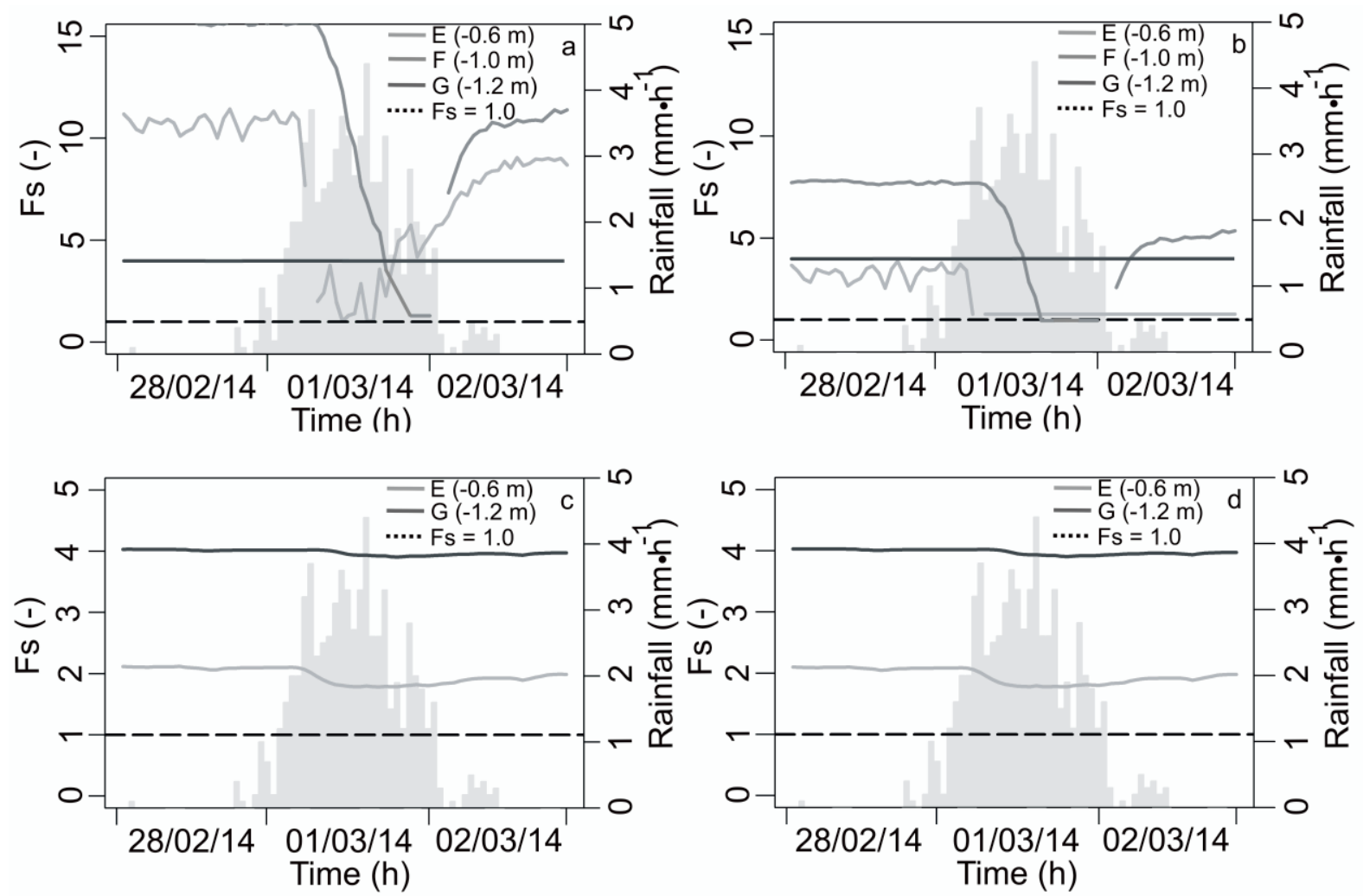

Figure 4. Modeled safety factor $\left(F_{s}\right)$ trends for the period of 28 February-2 March 2014: a) from water content with MDC parameters; b) from water content with MWC parameters; c) from pore water pressure with MDC parameters; d) from pore water pressure with MWC parameters.
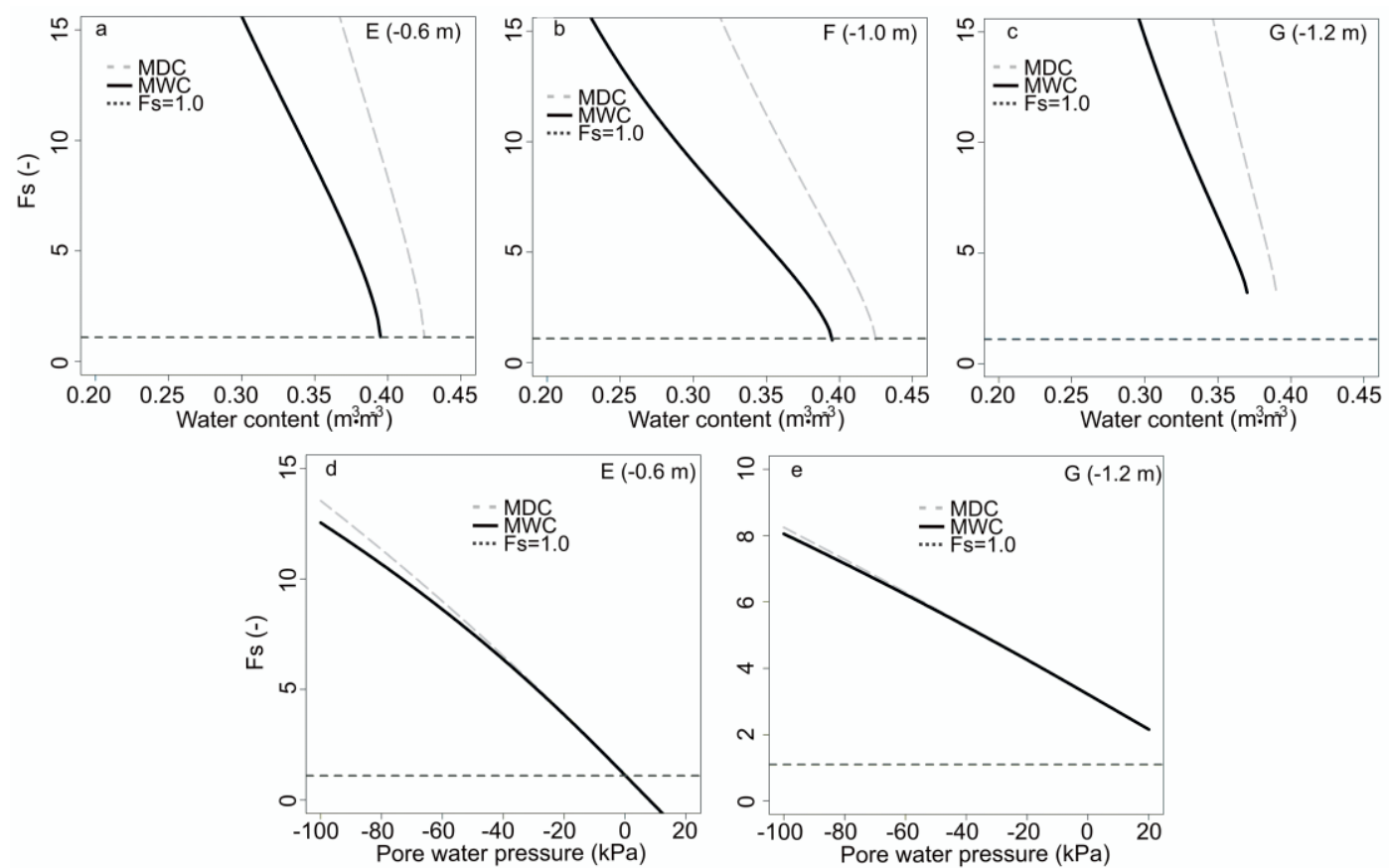

Figure 5. Lu and Godt's model safety factor $\left(F_{s}\right)$ as a function of water content $(a, b, c)$ or pore water pressure (d, e) for different soil levels of the test-site slope.

saturated condition of this horizon (Figs. 4a, b). At the same depth, the reconstructed safety factor on the basis of pore water pressure shows little variations, linked to little changes in field measured pore water pressure. This trend is similar by considering or not the hydrological hysteresis effects (Fig. 4c, d). In both cases the high soil cohesion $(29 \mathrm{kPa})$ is enough to keep the safety factor values in the stable range $\left(\mathrm{F}_{\mathrm{S}}>1\right)$.
At $0.6 \mathrm{~m}$ from the ground level, in the $\mathrm{E}$ horizon, safety factor calculated on the basis of field water content suction estimated by using MWC parameters decreases till values slightly higher than the unstable condition (Fig. 4b). Instead, by considering the reconstructions made on the basis of pore water pressure by using both MDC and MWC parameters, the safety factor keeps in the stable range with values around 2 (Fig. $4 \mathrm{c}, \mathrm{d}$ ). 
The effect of hydrological hysteresis seems to be more marked if the safety factor is estimated on the basis of water content data. In fact, at the same depth, some relevant differences (till more than 5.0 for safety factor values) between the reconstructions obtained by using either MDC or MWC parameters are evident if water content data are used (Fig. 4a, b). On the other hand, the differences given by considering or not the hysteresis in the modeling based on pore water pressure data are very limited, and are in the order of the second decimal term for the safety factor (Fig. 4c, d). In both cases, safety factor evaluated on the basis of drying parameters seems to model a higher contribution to the stability than the reconstructions on the basis of wetting parameters.

\subsection{Effects of hydrological parameters on safety factor trends}

Safety factor was calculated also from the other measured values of water content and pore water pressure along the monitoring time span (Fig. 5). The differences considering or not hydrological hysteresis are more evident when safety factor is modeled on the basis of soil water content (Fig. 5a, b, c). At values of soil water content close to saturation, MDC reconstructed safety factor is at least 3.0 times higher than that in wetting conditions. Moreover, safety factor curves as a function of soil water content do not connect at the lowest value, due to the presence of a not-closed hysteresis, with $\theta_{\mathrm{s}}$ of wetting curve lower than $\theta_{\mathrm{s}}$ of drying path (Fig. 5a, b, c).

The effects of taking into account the MDC properties with respect to the MWC ones are less evident for pore water pressure modeling (Fig. $5 \mathrm{~d}$, e). The gaps decrease till a complete convergence of the curves when pore water pressure reaches nil and then positive values (Fig. $5 \mathrm{~d}, \mathrm{e})$. This different behavior is due to the absence of $\theta_{\mathrm{s}}$ parameter on the formulation of suction stress estimation from pore water pressure (Eq. 3).

The safety factor estimated from pore water pressure can continue to decrease in the presence of positive pressure (Fig. 5d, e). Instead, the safety factor evaluated on the basis of the water content reaches a minimum constant value for soil water content equal to $\theta_{\mathrm{s}}$. For this reason, modeling the safety factor on the basis of water content can make a correct prediction of the failure at site-specific scale only when a shallow landslide develops in unsaturated conditions or in conditions of water content equal to the saturated water content, so that pore water pressure is less or equal to $0 \mathrm{kPa}$. In triggering conditions linked to the development of positive pressures, it is more appropriate modeling safety factor from pore water pressure. In this case, the modeling based on water content can only indicate conditions which lead to shallow landslides triggering, without a correct prediction of the failure instant.

\section{Conclusions}

Monitoring of a slope susceptible to shallow landslides is fundamental for identifying the main soil hydrological behaviors and the conditions which lead to soil failure. In the presented case study, the main triggering mechanism develops especially during wet seasons (winter and spring) and it is linked to an increase in water content till about $1 \mathrm{~m}$ from ground in correspondence of the most intense rainfalls (about $>60 \mathrm{~mm}$ in $48 \mathrm{~h}$ ).

Slope stability analysis using monitoring data correctly models the time instant and the depth of sliding surface formation. A better prediction occurs if hydrological hysteresis is taken into account, especially if safety factor is modeled using soil water content.

Modeling the safety factor on the basis of water content can make a correct prediction until a shallow landslide develops in conditions of water content equal to the saturated water content. In triggering conditions linked to the development of positive pore pressure, it is more appropriate modeling safety factor from pore water pressure, while the modeling based on water content can only indicate conditions which lead to the triggering, without a correct prediction of the failure instant.

These analyses at site-specific scale highlight the necessity of a correct choice of the models used for the slope stability analysis, also according to the most probable landslide triggering mechanism. For this reason, further developments will be the application of physically-based models based on water content and pore water pressure also in other monitored slope in different geological and environmental contexts, and also the application of these models at both local and regional scales.

\section{References}

1. D. Zizioli, C. Meisina, R. Valentino, L. Montrasio, Nat. Hazards Earth Syst. Sci. 13, 559-573 (2013)

2. T.T. Lim, H. Rahardjo, M.F. Chang, D.G. Fredlund, Can. Geotech. J. 33, 618-628 (1996)

3. M. Bittelli, R. Valentino, F. Salvatorelli, P. Rossi Pisa, Geomorphology 173-174, 161-173 (2012)

4. E. Damiano, L. Olivares L. Picarelli, Eng. Geol. 137-138, 1-12 (2012)

5. N. Lu, J.W. Godt, Water Resour. Res. 44, http://dx.doi.org/10.1029/2008WR006976 (2008)

6. S.M. Springman, A. Thielen, P. Kienzler, S. Friedel, Geotechnique 14, 1177-1193 (2013)

7. M. Bordoni, C.Meisina, R. Valentino, N. Lu, M. Bittelli, S. Chersich, Eng. Geol. 193, 19-37 (2015)

8. IUSS Working Group WRB, World Reference Base for Soil Resources (2014)

9. N. Lu, J.W. Godt, D.T. Wu, Water Resour. Res. 46, http://dx.doi.org/10.1029/2009WR008646 (2010)

10. M.T. Van Genuchten, Soil Sci. Soc. Am. J. 44, 892 898 (1980)

11. H.J. Vogel, U. Weller, O.J. Ippisch, J. Hydrol. 393, 20-28 (2010)

12. D.W. Marquardt, SIAM J. Appl. Math (1963 